\title{
Soluble amyloid triggers a myeloid differentiation factor 88 and interferon regulatory factor 7 dependent neuronal type- 1 interferon response in vitro
}

Myles Robert Minter, Bevan Scott Main, Kate Maree Brody, Moses Zhang, Juliet Marie Taylor and Peter John Crack

\begin{abstract}
Background: Neuro-inflammation has long been implicated as a contributor to the progression of Alzheimer's disease in both humans and animal models. Type-1 interferons (IFNs) are pleiotropic cytokines critical in mediating the innate immune pro-inflammatory response. The production of type-1 IFNs following pathogen detection is, in part, through the activation of the toll-like receptors (TLRs) and subsequent signalling through myeloid differentiation factor-88 (Myd88) and interferon regulatory factors (IRFs). We have previously identified that neuronal type-1 IFN signalling, through the type-1 interferon alpha receptor-1 (IFNAR1), is detrimental in models of AD. Using an in vitro approach, this study investigated the TLR network as a potential production pathway for neuronal type-1 IFNs in response to A 3 .

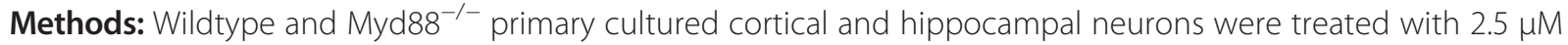
$\mathrm{A} \beta 1-42$ for 24 to $72 \mathrm{~h}$ or 1 to $10 \mu \mathrm{M}$ A $31-42$ for $72 \mathrm{~h}$. Human BE(2)M17 neuroblastoma cells stably expressing an IRF7 small hairpin RNA (shRNA) or negative control shRNA construct were subjected to $7.5 \mu \mathrm{M} A \beta 1-42 / A \beta 42-1$ for 24 to $96 \mathrm{~h}, 2.5$ to $15 \mu \mathrm{M}$ Aß1-42 for $96 \mathrm{~h}$ or $100 \mathrm{ng} / \mathrm{ml}$ LPS for 0.5 to $24 \mathrm{~h}$. Q-PCR was used to analyse IFNa, IFN 3 , IL-1 $\beta$, IL- 6 and TNFa mRNA transcript levels. Phosphorylation of STAT-3 was detected by Western blot analysis, and cell viability was assessed by MTS assay.
\end{abstract}

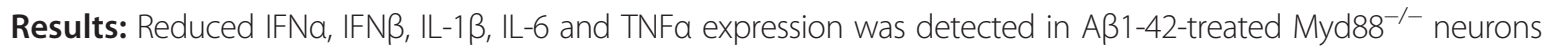
compared to wildtype cells. This correlated with reduced phosphorylation of STAT-3, a downstream type-1 IFN signalling mediator. Significantly, Myd88 ${ }^{-/-}$neuronal cultures were protected against A $\beta 1$-42-induced neurotoxicity compared to wildtype as determined by MTS assay. Knockdown of IRF7 in M17 cells was sufficient in blocking IFNa, IFN $\beta$ and p-STAT-3 induction to both A 1-42 and the TLR4 agonist LPS. M17 IRF7 KD cells were also protected against A 1 1-42-induced cytotoxicity.

Conclusions: This study confirms that the neuronal type-1 IFN response to soluble amyloid is mediated primarily through TLRs. This production is dependent upon Myd88 and IRF7 signalling. This study suggests that targeting this pathway to modulate neuronal type-1 IFN levels may be beneficial in controlling Aß-induced neurotoxicity.

Keywords: Type-1 interferon, Neuro-inflammation, Cytokines, JAK-STAT, Toll-like receptor, Myd88, IRF7, Amyloid, Alzheimer's disease

\footnotetext{
*Correspondence: juliett@unimelb.edu.au; pcrack@unimelb.edu.au

Department of Pharmacology and Therapeutics, University of Melbourne, 8th

floor, Medical building, Grattan St, Parkville, Melbourne 3010, VIC, Australia
} 


\section{Introduction}

Alzheimer's disease (AD) is the most common cause of dementia with over 44 million current sufferers worldwide. Intracellular hyperphosphorylated tau [1] protein and intercellular amyloid- $\beta$ (A $\beta$ ) plaque deposition [2] within the diseased brain remain the key histological abnormalities driving the proteinopathy, contributing to pyramidal neuronal loss. Features of neuro-inflammation are also evident in the AD brain. Activation and recruitment of microglia to $A \beta$ plaque deposits [3], reactive astrogliosis [4] and elevated pro-inflammatory cytokine load [5] have all been identified in human postmortem tissue and in both in vivo and in vitro models of AD. Severe neuro-inflammation, involving elevated pro-inflammatory cytokine load, can induce cellular apoptosis directly but can also alter the dynamics of physiological cell processes including the classical amyloid precursor protein (APP) processing pathway [6]. Tumour necrosis factor alpha (TNFo) regulates in vitro $\mathrm{A} \beta$ production and processing by triggering alterations in beta-site APP cleavage enzyme-1 (BACE-1) activity [7]. In addition, direct TNF $\alpha$-induced neurotoxicity mediated by interleukins (IL) also plays a major role in neurodegenerative disease [8]. A $\beta$ remains a potent endogenous agonist for pro-inflammatory cytokine production leading to activation of cultured microglia [9]. Recently, it has been reported that the amyloid-dependent activation of the NALP3 inflammasome in vivo is a critical pathway in producing IL- $1 \beta$ and triggering a multi-faceted neuro-inflammatory response [10]. Our laboratory recently identified a role for type- 1 interferon alpha receptor-1 (IFNAR1)-mediated signalling in A $\beta$-driven neuro-inflammation [11], known to interplay with NALP3 inflammasome activation $[12,13]$. The consequential cytokine storm triggers microglial activation and reactive astrogliosis creating a deleterious self-perpetuating neuroinflammatory response by contributing to both excessive $\mathrm{A} \beta$ production and direct neuro-degeneration.

The toll-like receptor signalling (TLR), a subset of the pattern recognition receptor (PRR) super-family, remains a major source of pro-inflammatory cytokine production. There are 13 TLR subtypes currently identified in humans and mice combined. Apart from endosomal TLR3 and TRIF-dependent TLR4 activation, all signalling is dependent upon the myeloid differentiation factor-88 (Myd88) adaptor protein [14]. Subsequent TLR signalling leads to activation of interferon regulatory factors (IRFs) and NFKB that in turn drives pro-inflammatory cytokine production $[15,16]$. Whilst receptor density is greatest in the lung and spleen, these receptors are also widely expressed in the brain albeit at lower levels [17]. Resident microglia express all TLR subtype mRNA to facilitate their role as the brain's 'macrophage'. Depending upon various stimuli from the CNS microenvironment, these polarising cells can coordinate an M1 (neuro- protective) or M2 (reparative) innate immune response. It is widely accepted that microglia are critical for CNS inflammation; however, neurons themselves also express all TLR subtypes [18] and actively contribute to the pathogeninduced response. Principally, the TLR system is responsible for detecting foreign pathogen components (lipopolysaccharides and viral genomic material) as well as endogenous material released from damaged tissue (heat shock proteins, hyaluronic acid and mRNA). Detection of these ligands initiates the commencement of an innate immune response by which microglia, astrocytes and indeed neurons produce cytokines, triggering removal of the foreign or damaged material. $A \beta$ has been identified as a novel endogenous ligand for many TLRs in the brain, triggering a neuro-inflammatory response (reviewed in [19]). Components of the TLR2 and TLR4 receptor complex are required for microglial detection of $A \beta$, mediating their phagocytic capacity [20,21]. Complete knockout of Myd88 in the $\mathrm{APP}_{\mathrm{SWE}} / \mathrm{PS}_{\triangle \mathrm{E} 9}$ mouse model of $\mathrm{AD}$ ameliorated $A \beta$ plaque burden, silenced microglial activation and reactive astrogliosis [22], and rescued some cognitive impairment [23]. In contrast, Myd88 heterozygous mice breed with $\mathrm{APP}_{\mathrm{SWE}} / \mathrm{PS}_{\triangle \mathrm{E} 9}$ mice displayed significant spatial memory deficits in the T-water maze paradigm and displayed elevated soluble A $\beta$ levels [24]. TLR4 mediates cytokine production in $\mathrm{APP}_{\mathrm{SWE}} / \mathrm{PS}_{\triangle \mathrm{E} 9}$ mice [25], and mutations to this PRR confer reductions in microglial activation and amyloid phagocytosis [26]. The A $\beta$-induced and TLR-mediated inflammatory response is critical in amyloid processing and disease progression; however unlike glia, how neurons conduct this response remains unclear.

Type- 1 interferons (IFNs), comprised of IFN $\alpha$ and IFN $\beta$, are cytokine proteins that play an important role in host immune response to infections, pathogens and various diseases (reviewed in [27]). These pleiotropic cytokines are produced via activation of numerous PRRs including the TLR network, retinoic acid-inducible gene-1 (RIG-1), melanoma differentiation-associated protein-5 (MDA-5) and interferon gamma-inducible protein-16 (IFI-16) [28,29]. Type-1 IFNs can drive a pro-inflammatory response by activating the JAK-STAT pathway, leading to secretion of hallmark neuro-inflammatory cytokines TNF $\alpha$, IL- 6 and IL-1 $\beta$. The myriad of cytokines and chemokines secreted provides a chemo-attractive environment, permitting cellular infiltration and inflammatory progression. Importantly, in the absence of type-1 IFN production and signalling, this inflammatory response fails to develop [30,31]. Although the Tyk-2/STAT pathway has been linked to soluble A $\beta 1$ 42 neurotoxicity [11,32], much remains unclear about type-1 IFN signalling in various cell types, including those in the brain.

It is critical to note that despite the complexity of type-1 IFN production, it all remains IRF dependent. The IRFs are well-characterised transcriptional regulators of 
the type-1 IFNs of which there have been nine mammalian isoforms identified. Of these nine, IRF3 and IRF7 are the key regulators of type- 1 IFN production and thus play a central role in innate immunity [33]. Specifically, IRF7 activation is required for IFN $\alpha$ production resulting in an effective immune response to a wide variety of pathogens [33]. IRF7 is localised to the cell cytoplasm in an inactive state and undergoes phosphorylation, interacts with various co-activators and translocates to the nucleus upon pathogenic insult [34]. Recently, it has been reported that IRF7 and other type-1 IFN-regulated genes are commonly mutated amongst the human population, altering the efficacy of an innate immune response to various pathogens [35]. Furthermore, the type-1 IFN response in ageing mice reduces BDNF levels and doublecortin positive cells in the dentate gyrus, shown to negatively influence cognition and hippocampal neurogenesis [36]. The TLR network is primarily responsible for the detection of pathogens and this remains a major process responsible for IRF7 activation (reviewed in [37]). This activation is mediated by critical adaptor proteins TRIF, TRAF, IRAK and Myd88 [38-41] and permits a positive feedback loop by which type-1 IFN production drives further expression of IRF7 $[42,43]$, exacerbating the innate immune response. The $A \beta$ peptide is detected, but not solely, by the TLR network and has potential to activate IRF7 in this manner, but how this unrecognised signalling influences the neuro-inflammatory response to amyloid has yet been addressed.

Recently, our laboratory reported the involvement of type-1 IFNs in the neuro-inflammatory response in $\mathrm{AD}$ [11]. Specifically, we identified that $A \beta 1-42$ initiates a deleterious type-1 IFN-mediated response in primary cultured neurons. This implicates the importance of neurons, not just microglia and astrocytes, in the inflammatory response to amyloid. In the current study, primary cultured murine neurons and human $\mathrm{BE}(2) \mathrm{M} 17$ neuroblastoma cells were used to investigate the TLR network as a potential source of this type-1 IFN response. The neuronal type-1 IFN production in response to A 1-42 was mediated through Myd88 and IRF7. Furthermore, when TLR signalling was compromised by in vitro removal of Myd88 or IRF7, cultures displayed reduced type-1 IFN levels and protection against A $\beta 1-42-$ induced cell death. This study highlights the key role of TLR signalling in the neuronal neuro-inflammatory response to amyloid, critical when targeting this receptor system therapeutically.

\section{Materials and methods Antibodies}

Primary antibodies used for Western blot analysis are the following: rabbit anti-p-STAT-3 (1:1,000, Cell Signalling, 9145S, Cell Signalling Technology, Danver, MA, USA), rabbit anti-STAT-3 (1:1,000, Cell Signalling, 4904S), mouse anti- $\beta$-actin (1:5,000, Sigma-Aldrich, A5441, SigmaAldrich, St. Louis, MO, USA). Secondary antibodies used for Western blot analysis are the following: horseradish peroxidase (HRP)-conjugated goat anti-rabbit (1:1,000, Dako, P0448, Agilent Technologies, Santa Clara, CA, USA) and goat anti-mouse (1:1,000, Dako, P0447).

\section{Mice}

All animal experiments complied with the regulatory standards of, and were approved by, the University of Melbourne, Faculty of Medicine, Dentistry and Health Sciences Animal Ethics Committee (Ethics \#1212477). Myd88 ${ }^{-/-}$mice on a pure $\mathrm{C} 57 \mathrm{Bl} / 6$ background were generated by and kindly sourced from Prof. Shizuo Akira [44] and were mated for E14 to E16 pregnancy. Wildtype $\mathrm{C} 57 \mathrm{Bl} / 6$ time-mated females where sourced from the Animal Resources Centre (ARC, Western Australia).

\section{Mixed cortical and hippocampal neuron isolation}

Mixed cortical and hippocampal neurons were isolated from embryonic day 14 to 16 embryos as previously described [45]. Briefly, cortices were dissected from the foetal brains and the meningeal layers removed. Tissue was then mechanically processed and treated with trypsin (Sigma-Aldrich, T9201) and DNAse (Sigma-Aldrich, D5025) in Krebs solution (supplemented with 0.3\% BSA $\mathrm{w} / \mathrm{v}$ and $176 \mathrm{nM} \mathrm{MgSO}_{4}$ ) to produce a single-cell suspension. Cells were allowed to adhere for $2 \mathrm{~h}$, to remove potential contaminating fibroblasts and glia, before cultures were plated at $10^{6}$ cells $/ \mathrm{ml}$ in plating media (Neurobasal media containing B27 supplement (Gibco, 17504-044, Life Technologies, Carlsbad, CA, USA) and 2\% FBS). The following day, FBS was removed from the media and cultures were supplemented with fresh culture media (Neurobasal media containing B27 supplement) every 2 days until treatment. Cultures were treated at 7 days in vitro. Purity of cultures was confirmed to be $>95 \%$ neurons by NeuN and GFAP staining to identify neurons and glia, respectively.

\section{M17 neuroblastoma cells}

Human BE(2) M17 neuroblastoma cells (ATCC number: CRL-2267 $\left.{ }^{\mathrm{Tm}}\right)$ were cultured in T75 flasks with culture medium (OptiMEM (Gibco), 5\% FBS, 0.5\% penicillinstreptomycin (Gibco)) at $37^{\circ} \mathrm{C} / 5 \% \mathrm{CO} 2$ until $90 \%$ confluent. Cells were plated at $2 \times 10^{5}$ cells $/ \mathrm{ml}$ in 6 -cm dishes for $24 \mathrm{~h}$ prior to treatment.

\section{Generation of M17 IRF7 knockdown cell line}

IRF7 knockdown (IRF7 KD) and negative control (NC) knockdown M17 cells were generated using commercially available small hairpin RNA (shRNA) plasmid constructs (Origene, Rockville, MD, USA). Briefly, M17 cells were transfected using Fugene ${ }^{\circ} \mathrm{HD}$ (Promega, Madison, WI, USA) with HuSH shRNA plasmids containing an 
IRF7 specific shRNA cassette or non-effective 29-mer scrambled shRNA cassette. Clonal cell lines were generated using the selectable marker puromycin $(0.5 \mu \mathrm{g} / \mathrm{ml}$, Gibco, A11138-03). Successful knockdown of IRF7 (>70\%) was confirmed by QPCR where IRF7 levels in IRF7 KD M17 cells were compared to their NC M17 cell counterparts (Additional file 1: Figure S1).

\section{Amyloid-beta preparation and treatment}

Amyloid peptide stocks were generated according to protocol by [46]. The amyloid- $\beta$ (A $\beta$ ) 1-42 (peptide corresponding to amino acids 1 to 42 , GenecBio, A-42-T-1) peptide was initially reconstituted in 1,1,1,3,3,3-hexafluoro-2-propanol at $0.5 \mathrm{mg} / \mathrm{mL}$, lyophilised, and stored at $-80^{\circ} \mathrm{C}$ until required. The peptide was then dissolved in a $5 \mathrm{mM} \mathrm{NaOH}$ vehicle and protein concentration determined by absorbance spectrophotometry at $214 \mathrm{~nm}$ as previously described [47]. This enhances the $A \beta$ peptide solubility and lengthens the time frame in which toxicity is induced $[46,48-51]$. These preparations lead to globular aggregate structures that resemble the oligomeric confirmation rather than elongated fibril structures [52-54]. Primary neuronal cultures were then treated with 0.5 to $10 \mu \mathrm{M} \mathrm{A} \beta 1-42$ or vehicle for up to 72 $\mathrm{h}$ in treatment medium (Neurobasal media containing anti-oxidant free B27 supplement (Gibco, 10889038)). M17 NC shRNA and M17 IRF7 KD cell cultures were treated with 2.5 to $15 \mu \mathrm{M} \mathrm{A} 1-42$ for up to $96 \mathrm{~h}$ in fresh serum-reduced culture medium ( $2 \%$ FBS $)$. The final $\mathrm{NaOH}$ concentration in the culture medium was $<5 \mathrm{nM}$ and shown to be non-toxic.

\section{Lipopolysaccharide preparation and treatment}

Lipopolysaccharides from Escherichia coli 026:B6 (LPS, Sigma-Aldrich, L8274) were initially reconstituted in phosphate-buffered saline (PBS) to yield a concentration of $1 \mathrm{mg} / \mathrm{ml}$, and aliquots were stored at $-80^{\circ} \mathrm{C}$ until required. M17 human neuroblastoma cells were then treated with $100 \mathrm{ng} / \mathrm{ml} \mathrm{LPS} \mathrm{for} 0.5$ to $24 \mathrm{~h}$ in fresh serum-reduced culture medium ( $2 \% \mathrm{FBS})$.

\section{Protein extraction}

Following treatment, primary neuronal and M17 cell cultures were collected via cell scraping in ice-cold PBS. After centrifugation at 5,000 g, cell pellets were sonicated in lysis buffer $(50 \mathrm{mM}$ tris, $1 \%$ Triton $\mathrm{x}-100,1 \%$ SDS, PhosphoSTOP ${ }^{\circ}$ and protease inhibitors (Roche, Basel, Switzerland), $\mathrm{pH}$ 7.4) and protein concentrations determined by Bradford assay (Bio-Rad, Hercules, CA, USA).

\section{Western blot analysis}

A $50 \mu \mathrm{g}$ of protein was resolved on $10 \%$ acrylamide SDS PAGE gels and transferred to polyvinylidene fluoride (PVDF) membranes by semi-dry transfer. Membranes were blocked with $5 \% \mathrm{w} / \mathrm{v}$ skim milk powder in TBS-T for $1 \mathrm{~h}$ at room temperature $\left(\approx 20^{\circ} \mathrm{C}\right)$ before overnight incubation with primary antibodies at $4^{\circ} \mathrm{C}$. Membranes were washed in TBS-T before being incubated with HRPconjugated secondary antibodies (diluted in $5 \%(\mathrm{w} / \mathrm{v})$ BSA in TBS-T) for $120 \mathrm{~min}$ at room temperature $\left(\approx 20^{\circ} \mathrm{C}\right)$. After additional washing in TBS-T, signals were detected using an $\mathrm{ECL}^{\mathrm{Tw}}$ prime Western blotting detection kit (Amersham, RPN2232, GE Healthcare, Little Chalfont, UK) and visualised using the ChemiDoc ${ }^{\text {tm }}$ MP system (Bio-Rad).

\section{RNA isolation and cDNA synthesis}

Cells were lysed in TRIzol ${ }^{\circ}$ (Life Technologies, 15596018) and RNA isolated per manufacturer's instructions with concentrations determined by the Nanodrop 1000 spectrophotometer (Thermo Scientific, Waltham, MA, USA). A $1 \mu \mathrm{g}$ quantity of RNA was reversed transcribed into cDNA using a high-capacity cDNA reverse transcription kit (Applied Biosystems, Life Technologies, USA, 4368814) according to manufacturer guidelines. cDNA was diluted 1:3 in DEPC-treated $\mathrm{dH}_{2} \mathrm{O}$ for use in quantitative PCR (Q-PCR).

\section{Quantitative PCR (Q-PCR)}

All Q-PCR was performed in standard 384-well plates using the $7900 \mathrm{HT}$ fast real-time PCR system (Applied Biosystems, Life technologies, USA). Taqman probes (Applied Biosystems, Life technologies, USA) were used

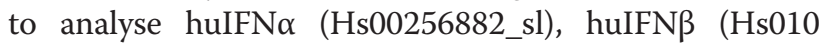
77958_sl), UBC (Hs00824723_m1), muGAPDH (Mm99 999915_m1), muIFN $\beta$ (Mm00439552_s1), muIL-1 $\beta$ (Mm 01336189_m1), mulL-6 (Mm00446190_m1) and muTNFo (Mm00443258_m1) under the following cycle parameters: $50^{\circ} \mathrm{C}$ for $2 \mathrm{~min}, 94.5^{\circ} \mathrm{C}$ for $10 \mathrm{~min},\left(97^{\circ} \mathrm{C}\right.$ for $30 \mathrm{~s}, 59.7^{\circ} \mathrm{C}$ for $60 \mathrm{~s}) \times 40$ repeats. The SYBR green system was used to analyse muIFN $\alpha$ and muGADPH using the following primer sequences (Geneworks, Hindmarsh, SA, Australia): GADPH forward: 5' ATCTTCTTGTGCAGTGCCAGC 3', GADPH reverse: 5' ACTCCACGACATACTCAGC ACC 3', muIFN $\alpha$ forward: 5' GCAATCCTCCTAGACT CACTTCTGCA 3', muIFN $\alpha$ reverse 1: 5' TATAGTT CCTCACAGCCAGCAG $3^{\prime}$, muIFN $\alpha$ reverse 2: 5' TATTTCTTCATAGCCAGCTG 3', muTLR2 forward: $5^{\prime}$ TGCTTTCCTGCTGAAGATTT 3', muTLR2 reverse: 5' TGTACCGCAACAGCTTCAGG 3', muTLR4 forward: 5' ACCTGGCTGGTTTACACGTC 3', muTLR4 reverse: 5' TGTCCAGAGACATTGCAGAA 3'. SYBR green Q-PCR was then performed under the following temperature regulations: $95^{\circ} \mathrm{C}$ for $20 \mathrm{~min},\left(95^{\circ} \mathrm{C}\right.$ for $30 \mathrm{~s}$, $60^{\circ} \mathrm{C}$ for $\left.90 \mathrm{~s}\right) \times 40$ repeats, $95^{\circ} \mathrm{C}$ for $15 \mathrm{~min}, 60^{\circ} \mathrm{C}$ for 15 min, $95^{\circ} \mathrm{C}$ for $15 \mathrm{~min}$. Fold change in mRNA levels were then calculated using the $\Delta \Delta \mathrm{ct}$ method $\left(2^{-\Delta \Delta \mathrm{Ct}}\right)$ [55]. Cycle threshold $(\mathrm{Ct})$ values were obtained from the linear gradient section of each fluorescent PCR amplification curve. 
The $\mathrm{Ct}$ values of each individual reaction triplicate for genes of interest were then normalised back to the GAPDH housekeeping gene, yielding $\Delta \mathrm{Ct}$ values. The calculated $\Delta \mathrm{Ct}$ of the $\mathrm{A} \beta$ treatment groups were then normalised against respective genotype-specific vehicle control samples $(\Delta \Delta \mathrm{Ct})$. As all $\Delta \Delta \mathrm{Ct}$ values were calculated from the linear gradient amplification curve, conferring $100 \%$ enzymatic efficiency, and PCR is an exponential process, $\Delta \Delta \mathrm{Ct}$ values were then converted to fold change (fold change $=2^{(-\Delta \Delta C t)}$ ). All Q-PCR data expressed throughout this publication has been calculated using this method.

\section{MTS assay}

Cell viability was measured by the cellular ability to metabolise 3-(4,5-dimethylthiazol-2-yl)-5-(3-carboxymethoxyphenyl)-2-(4-sulfophenyl)-2H-tetrazolium (MTS) (Promega) in the presence of phenazine methosulfate to a formazan product, as described previously [56]. Viability of treated samples was expressed as a percentage of light absorbance at $490 \mathrm{~nm}$ of the vehicle control, with all experiments performed in triplicate. Staurosporine $(1 \mu \mathrm{M})$ was used to induce cellular apoptosis and used as a positive control for apoptotic cell death in the neuronal cultures.

\section{Statistical analysis}

For all Q-PCR, MTS assay and Western blot densitometry data, an unmatched two-way ANOVA was performed for each time point/concentration with cellular genotype as the fixed variable. A Bonferroni post hoc test was then used to determine statistical significance $(p<0.05)$ between genotype groups. Graphical data is displayed as mean \pm SEM.

\section{Results}

The type- 1 IFN response to $A \beta 1-42$ is Myd88 dependent in primary cultured neurons

Previously, we have confirmed that neurons alone are capable of initiating a type-1 IFN response to soluble amyloid [11]. The TLR system has previously been implicated in the detection of soluble amyloid [57], and classical TLR signalling leads to production of type-1 IFNs. We confirm that TLR4 and TLR2, albeit at lower levels, are expressed in our primary cultured mixed cortical and hippocampal neurons (Additional file 2: Table S1). A critical adapter protein required for the majority of TLR-mediated signalling is Myd88; thus, we used Myd88 ${ }^{-/-}$neuronal cultures to investigate the source of type- 1 IFN production in response to A $31-42$. Wildtype and Myd88 $8^{-/-}$neurons were treated with $2.5 \mu \mathrm{M}$ A $\beta 1-42$ for 24 to $72 \mathrm{~h}$. This $\mathrm{A} \beta 1-42$ concentration routinely gives $\approx 50 \%$ cell death, thus simulating amyloid neurotoxicity and allowing surviving cells to react to the neuro-inflammatory environment [11]. Q-PCR identified

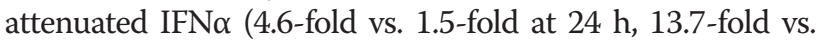

2.5 -fold at $72 \mathrm{~h}$, Figure $1 \mathrm{~A}$ ) and IFN $\beta$ (3.1-fold vs. 1.3-fold at $24 \mathrm{~h}, 7.0$-fold vs. 2.6-fold at $72 \mathrm{~h}$, Figure $1 \mathrm{~B}$ ) mRNA transcript levels in A $\beta 1-42$-treated Myd88 ${ }^{-1-}$ cultures compared to wildtype. Type-1 IFNs directly stimulate the JAKSTAT cascade to initiate pro-inflammatory cytokine transcription; hence, we investigated the phosphorylation of STAT-3 in these cultures. Western blot identified elevated tyrosine 705 phosphorylation of STAT-3, at 24 and $72 \mathrm{~h}$, in A $\beta 1$-42-treated wildtype neuronal cultures. Densitometry confirmed that this phosphorylation was significantly reduced in Myd88 ${ }^{-/-}$neuronal cultures (1.4-fold vs. 0.5-fold at $24 \mathrm{~h}, 5.3$-fold vs. 2.8 -fold at $72 \mathrm{~h}$, Figure $1 \mathrm{C,D}$, Additional file 3: Figure S3). Synthetic peptides [58] and potential endotoxin contaminants [59] possess the ability to act as DAMPs and in turn trigger an immune response. To confirm that the observed type- 1 response is A $\beta 1-42$ specific and not an artefact response from a foreign peptide, neuronal cultures were also treated with the control A $\beta 42-1$ peptide. Significantly, neuronal A $\beta 42-1$ treatment failed to generate type-1 IFN expression (Additional file 4: Figure S2A) and STAT-3 phosphorylation (Additional file 4: Figure $\mathrm{S} 2 \mathrm{~B}$ ) in WT neurons indicating that this innate immune response is $A \beta 1-42$ specific. This data confirms that neurons alone have the capacity to initiate a type- 1 IFN response specifically against the A $\beta 1-42$ peptide. This response is dependent upon Myd88 signalling, a critical adaptor protein in the TLR network.

\section{Hallmark pro-inflammatory type-1 IFN-regulated cytokine expression is reduced in $\mathrm{Myd} 88^{-/-}$neuronal cultures following $A \beta 1-42$ insult}

The products of type-1 IFN-driven JAK-STAT signalling are a myriad of pro-inflammatory cytokines that in turn drive the innate immune response. Interleukins and TNF $\alpha$ are critical cytokines in potentiating this immune response and are upregulated in settings of amyloid pathology [60]; thus, we assessed their expression in $\mathrm{Myd} 88^{-/-}$neuronal cultures. Wildtype and Myd $88^{-1-}$ neurons were treated with $2.5 \mu \mathrm{M} A \beta 1-42$ for 24 to $72 \mathrm{~h}$. Expression of the hallmark pro-inflammatory cytokines IL-1 $\beta$ (3.2-fold vs. 1.3fold at $24 \mathrm{~h}$, Figure 2A), IL-6 (21.4-fold vs. 3.0-fold at $24 \mathrm{~h}$, Figure 2B) and TNF $\alpha$ (3.2-fold vs. 1.0-fold at $24 \mathrm{~h}, 4.6$-fold vs. 1.0 -fold at $48 \mathrm{~h}, 6.3$-fold vs. 1.7 -fold at $72 \mathrm{~h}$, Figure $2 \mathrm{C}$ ) were decreased in $\mathrm{Myd} 88^{-/-}$neurons compared to wildtype cultures in response to $A \beta 1-42$. This data confirms a neuronal source of hallmark pro-inflammatory cytokine secretion in response to amyloid. This response, comprised of interleukins and TNF $\alpha$, is governed by TLR-Myd88dependent signalling.

\section{Removal of Myd88 confers protection against $A \beta 1-42$ toxicity in primary cultured neurons}

To investigate the overall effect of reducing type-1 IFN production and signalling through removal of Myd88, 

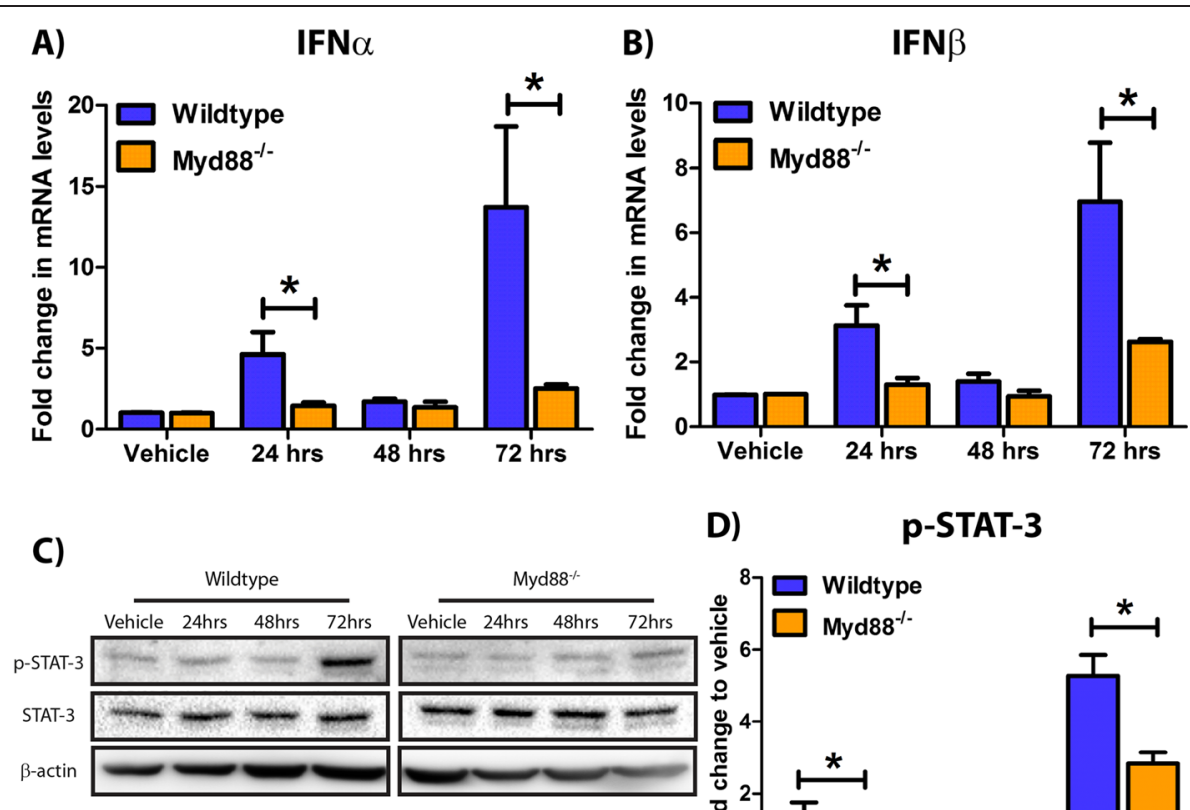

D)

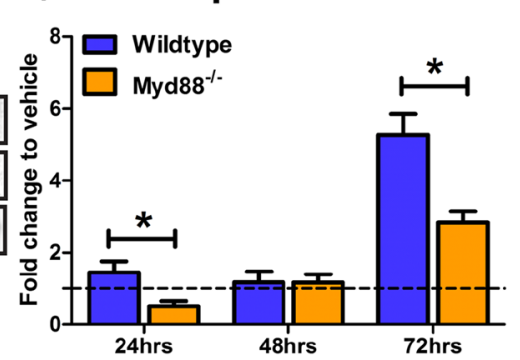

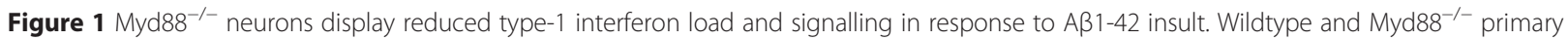

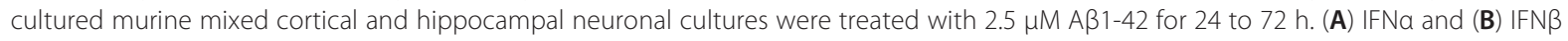
mRNA levels were analysed by Q-PCR ( ${ }^{*} p<0.05, n=5$ to 6 , unmatched two-way ANOVA, Bonferroni post hoc test). (C) STAT-3 tyrosine 705 phosphorylation of whole cell extracts was measured by Western blot. (D) Corresponding densitometry $\left(^{*} p<0.05, n=5\right.$, unmatched two-way ANOVA, Bonferroni post hoc test). For densitometry calculations, phosphorylation intensity was measured in arbitrary units (A.U.) and normalised to the STAT-3:B-actin intensity ratio. All graphical data is displayed as mean \pm SEM with treatment time on the $x$ axis. Full-size uncropped Western blots can be viewed in Additional file 4: Figure S2.

cultures were treated with 1 to $10 \mu \mathrm{M} A \beta 1-42$ for $72 \mathrm{~h}$ and neuronal viability was measured by MTS assay. Myd $88^{-/-}$neurons were significantly less susceptible to A $31-42$-induced neurotoxicity compared to wildtype cells $(69.9 \%$ vs. $86.1 \%$ viability with $2.5 \mu \mathrm{M}, 56.8 \%$ vs. $80.4 \%$ viability with $5 \mu \mathrm{M}, 44.3 \%$ vs. $58.8 \%$ viability with $10 \mu \mathrm{M}$, Figure 3). No difference in viability between genotypes in response to the apoptosis-inducing staurosporine was identified. This finding suggests that a reduction in type-1 IFN and hallmark pro-inflammatory cytokines, via removal of Myd88, confers protection against soluble amyloid cytotoxicity.

The type-1 IFN response to $A \beta 1-42$ is IRF7 dependent and mimics an LPS-induced type-1 IFN signature in human $\mathrm{BE}(2) \mathrm{M} 17$ neuroblastoma cells

IRF7 has been reported as the critical mediator of type-1 IFN production and is a major downstream signalling molecule in Myd88-dependent and independent TLR cascades [61]. To investigate if IRF7 is critical in soluble amyloid-driven type-1 IFN production in human M17 neuroblastoma cells, we established a stable IRF7 shRNA cell line and treated with $7.5 \mu \mathrm{M} A \beta 1-42$ for 24 to $72 \mathrm{~h}$. Q-PCR identified decreased IFN $\alpha$ (3.1-fold vs. 0.5-fold at $48 \mathrm{~h}, 3.8$-fold vs. 0.8 -fold at $72 \mathrm{~h}, 3.9$-fold vs. 1.2 -fold at
$96 \mathrm{~h}$, Figure 4A) and IFN $\beta$ (1.9-fold vs. 0.6-fold at $48 \mathrm{~h}$, 2.3 -fold vs. 0.8 -fold at $72 \mathrm{~h}, 2.9$-fold vs. 1.1 -fold at $96 \mathrm{~h}$, Figure 4B) mRNA transcript levels in A $\beta 1$-42-treated M17 IRF7 KD cells compared to M17 NC shRNA cultures. This data is supported by similar findings using an alternative M17 IRF7 KD clonal cell line with 77\% knockdown efficiency (Additional file 5: Figure S4). As the amyloid peptide is detected by many TLR isoforms, we utilised LPS to ascertain a TLR4-specific type-1 IFN response profile and compared this to the $A \beta 1-42$ data. IRF7 KD shRNA and NC shRNA M17 cells were treated with $100 \mathrm{ng} / \mathrm{ml}$ LPS for $30 \mathrm{~min}$ to $24 \mathrm{~h}$. Q-PCR showed decreased IFNa (5.2-fold vs. 0.6 -fold at $30 \mathrm{~min}, 4.2$-fold vs. 1.0 -fold at $1 \mathrm{~h}, 6.8$-fold vs. 0.7 -fold at $2 \mathrm{~h}$, Figure $4 \mathrm{C}$ ) and IFN $\beta$ (2.4-fold vs. 1.1-fold at 2 hours, 2.8 -fold vs. 1.0 -fold at 24 hours, Figure 4D) mRNA levels in LPSstimulated M17 IRF7 KD cells compared to NC shRNA cultures. Western blot analysis identified a trend for decreased STAT-3 phosphorylation levels at $24 \mathrm{~h}$ (5.0-fold vs. 3.4-fold, $t=2.064, \mathrm{DF}=5$ ) and a significant reduction at $72 \mathrm{~h}$ (6.2-fold vs. 3.1-fold) post-A $\beta 1-42$ treatment in M17 IRF7 KD cells compared to NC cultures (Figure 4E,F, Additional file 6: Figure S5). Similarly, LPSinduced STAT-3 phosphorylation levels were reduced at $2 \mathrm{~h}$ (4.9-fold vs. 2.7-fold) and 24 hours (6.9-fold vs. 2.0- 


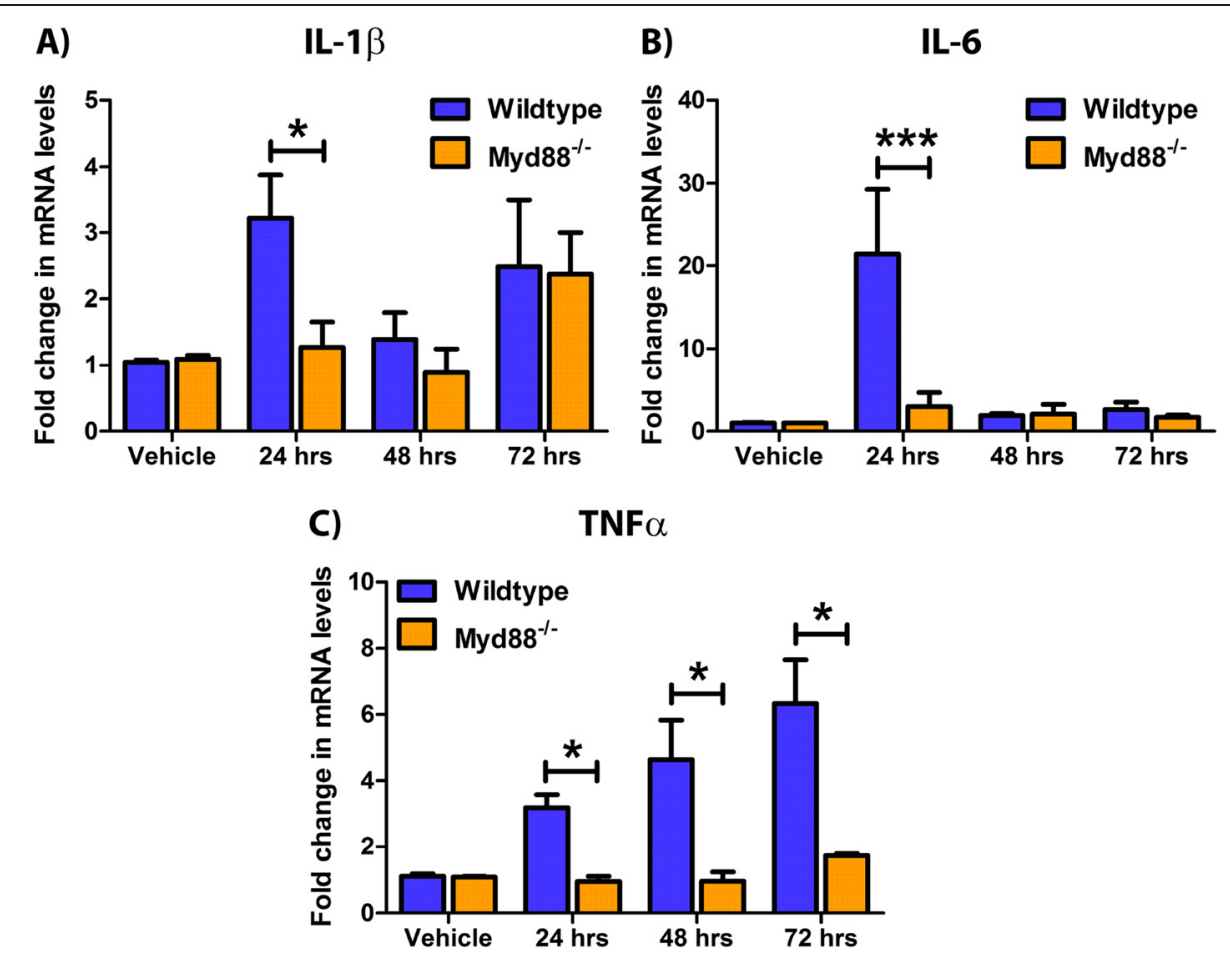

Figure 2 Removal of Myd88 in Aß1-42-treated neuronal cultures confers reductions in hallmark pro-inflammatory cytokine secretion. Wildtype and $\mathrm{Myd} 88^{-/-}$primary cultured murine mixed cortical and hippocampal neuronal cultures were treated with $2.5 \mu \mathrm{M}$ A $31-42$ for 24 to $72 \mathrm{~h}$. Q-PCR was performed to analyse (A) IL-1 $\beta$, (B) IL-6, and (C) TNFa mRNA transcript levels ${ }^{*} p<0.05,{ }^{* * *} p<0.001, n=5$ to 6 , unmatched two-way ANOVA, Bonferroni post hoc test). All data is displayed as mean \pm SEM with treatment time on the $x$ axis.

fold) in the M17 IRF7 KD cells (Figure 4G/H, Additional file 7: Figure S6). This data confirms that both type-1 IFN responses to the peptide TLR ligand, $A \beta 1-42$ and the TLR4 selective agonist, LPS, are IRF7 dependent in human BE(2) M17 neuroblastoma cells. This finding implies that TLR4 detection of amyloid and IRF7 signalling contributes to the net neuronal type-1 IFN response to soluble amyloid.

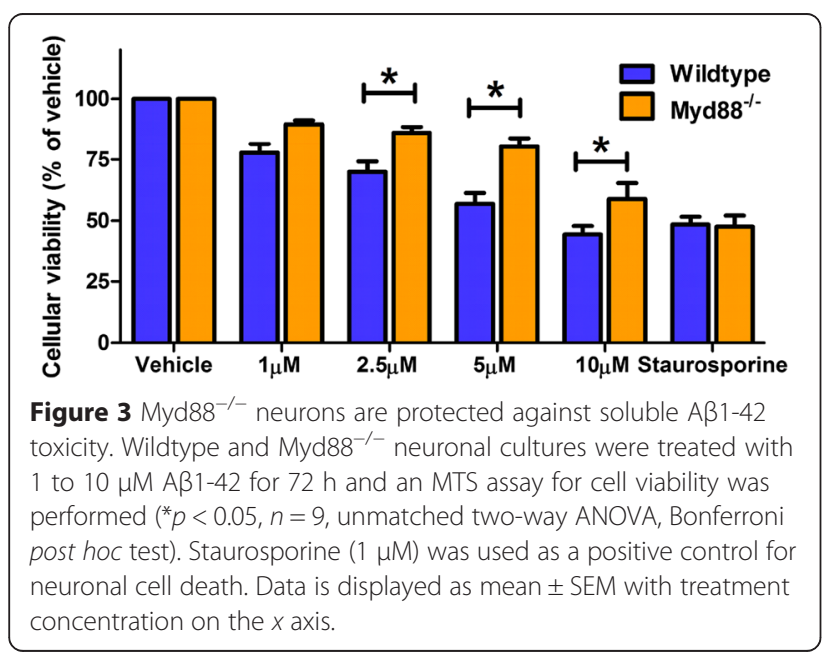

Reduction of IRF7 levels confers protection against $A \beta 1-42$ toxicity in human $B E(2)$ M17 neuroblastoma cells Previously, and in the current study, we have reported that reducing type-1 IFN secretion in response to amyloid in neuronal cultures affords cellular protection [11]. Thus, we assessed the effect on cytotoxicity of decreased type-1 IFN production and signalling in response to A 11-42 using M17 IRF7 KD cells. M17 IRF7 KD cells and NC shRNA cultures were treated with 2.5 to $15 \mu \mathrm{M}$ A $\beta 1-42$ for $96 \mathrm{~h}$, and an MTS assay was performed to evaluate cellular viability. M17 IRF7 KD cells were significantly protected against $7.5 \mu \mathrm{M}$ A $\beta 1-42$ (61.8\% vs. $103.1 \%$ viability) compared to their NC shRNA counterparts with a protective effect also suggestive at $10 \mu \mathrm{M}$ A $\beta 1-42 \quad(40.5 \%$ vs. $62.3 \%$ viability, $t=2.128, \quad \mathrm{DF}=4)$ (Figure 5). This data suggests that reducing IRF7dependent production of type-1 IFNs in response to $\mathrm{A} \beta 1-42$ confers a protective phenotype in human $\mathrm{BE}(2)$ M17 neuroblastoma cells.

\section{Discussion}

Deposition of the $A \beta$ peptide and formation of insoluble plaques are hallmark pathologies associated with $\mathrm{AD}$. However, the extent of plaque formation fails to correlate with disease progression [62] and therefore it has been considered that the soluble amyloid oligomers are 

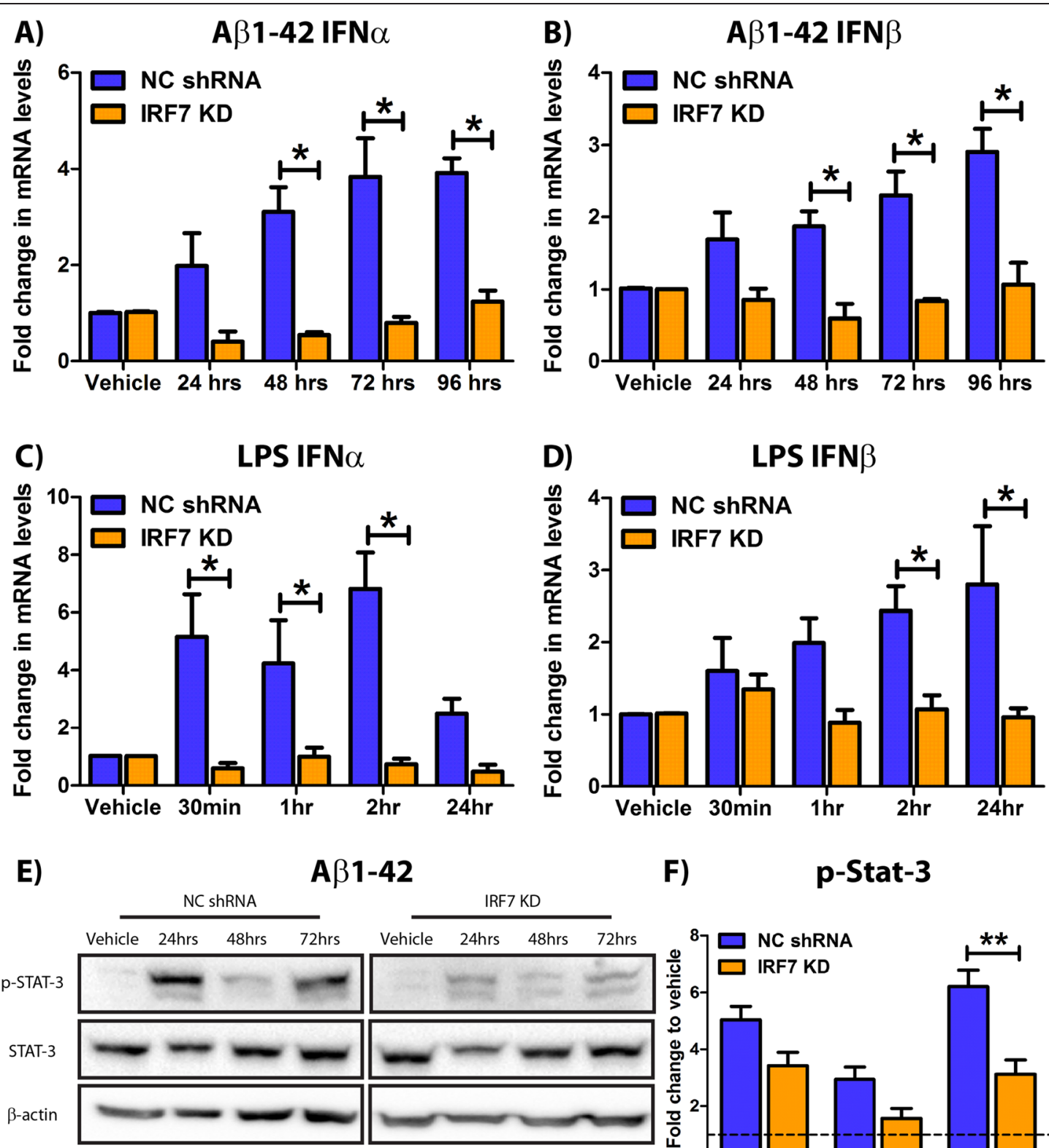

F)
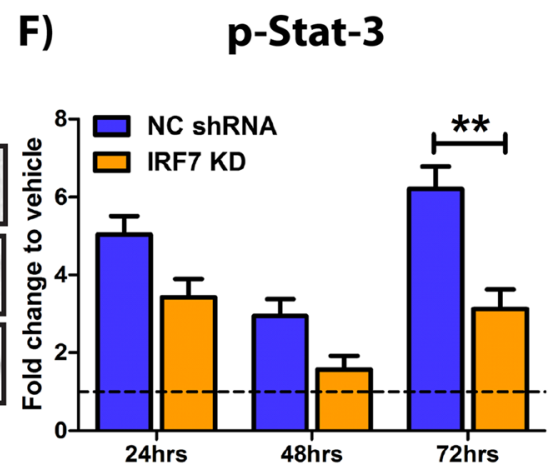

G)

LPS

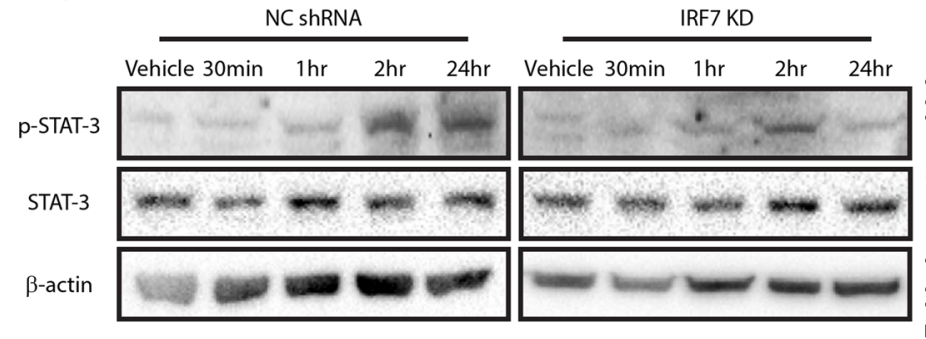

H)
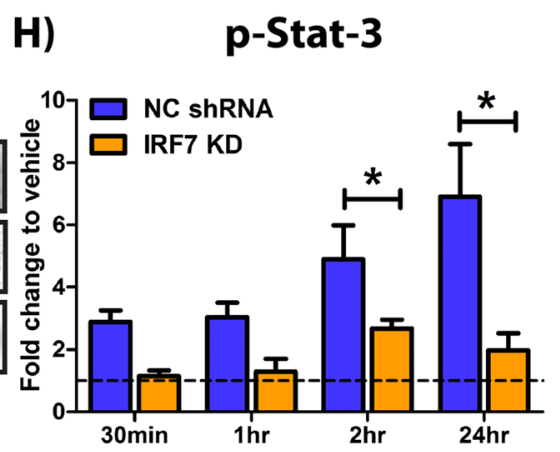

Figure 4 (See legend on next page.) 
(See figure on previous page.)

Figure 4 The neuronal type-1 IFN response to A 1-42 is IRF7 dependent and mimics an LPS-induced interferon signature. Human BE(2) M17 neuroblastoma cells, transfected with an IRF7 knockdown (KD) construct or negative control (NC) plasmid, were treated with $7.5 \mu \mathrm{M}$ A 1 -42 for 24 to 96 h. Q-PCR was performed to analyse (A) IFNa and (B) IFN $\beta$ mRNA levels post-treatment $\left({ }^{*} p<0.05, n=9\right.$ to 12, unmatched two-way ANOVA, Bonferroni post hoc test, alternative clone data can be viewed in Additional file 4: Figure S2). Cells were treated with 100 ng/ml LPS for 0.5 to $24 \mathrm{~h}$ and (C) IFNa and (D) IFN $\beta$ mRNA levels were analysed by Q-PCR ${ }^{*} p<0.05, n=7$ to 9, unmatched two-way ANOVA, Bonferroni post hoc test). (E) The phosphorylation of STAT-3 in the AB1-42-treated cultures was analysed by Western blot analysis. (F) Corresponding densitometry. (** $p<0.01, n=6$, unmatched two-way ANOVA, Bonferroni post hoc test). (G) The protein lysates of the LPS-treated cells were also analysed for STAT-3 phosphorylation by Western blot with $(\mathbf{H})$ corresponding densitometry $\left({ }^{*} p<0.05, n=12\right.$, unmatched two-way ANOVA, Bonferroni post hoc test). For densitometry calculations, phosphorylation intensity was measured in arbitrary units (A.U.) and normalised to the STAT-3: $\beta$-actin intensity ratio. All graphical data is displayed as mean \pm SEM with treatment time on the $x$ axis. Full-size uncropped Western blots of A 3 - and LPS-treated cultures can be viewed in Additional file 6: Figure S5 and Additional file 7: Figure S6, respectively.

the primary neurotoxic species contributing to the neuro-degeneration $[63,64]$. The precise mechanisms of soluble $A \beta$-induced neurotoxicity however are still poorly understood. Neuro-inflammation has been implicated in $\mathrm{AD}$ progression, but the exact contribution of each CNS-residing cell type in this response remains unclear. Microglia, the resident inflammatory cells of the CNS, remain critically important for the clearance of $A \beta$; however, it is ultimately the neuronal populations that respond detrimentally to the neuro-inflammatory environment in $\mathrm{AD}$ and are indeed the cells lost in the pathology $[65,66]$. We have previously established a role for type- 1 IFNs in animal and cell models of $A \beta$ toxicity [11]. Specifically, we identified neuronal populations as a source of type- 1 IFN secretion in response to soluble $A \beta$ insult. This current study investigated TLR signalling pathways as a potential origin for this neuronal type-1 IFN response to $A \beta$. Myd88 remains a critical adaptor protein in the majority of TLR pathways and drives IRF7 activation, in turn upregulating the expression and subsequent production of type-1 IFNs. Type-1 IFN secretion and downstream signalling via p-STAT-3 was downregulated in $\mathrm{Myd} 88^{-/-}$primary neurons following A $\beta 1-42$ challenge. This finding correlated with reductions

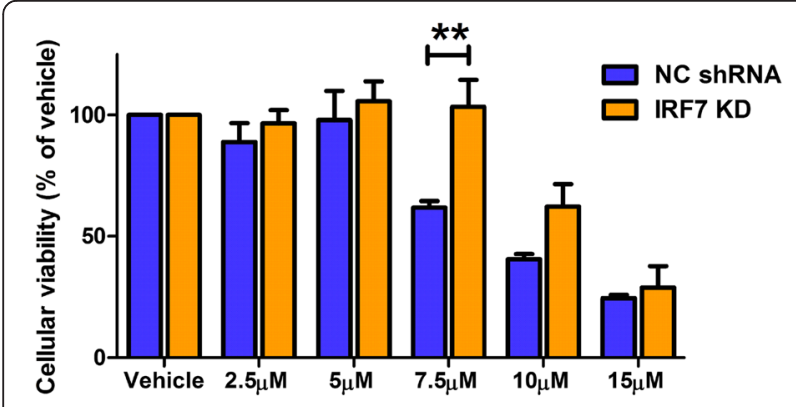

Figure $\mathbf{5}$ Knockdown of IRF7 in human BE(2) M17 neuroblastoma cells confers protection against A 1 1-42. Human BE(2) M17 neuroblastoma cells, transfected with an IRF7 knockdown (KD) construct or negative control (NC) plasmid, were treated with 2.5 to $15 \mu \mathrm{M} \mathrm{A} \beta-42$ for $72 \mathrm{~h}$ and an MTS assay to measure cell viability was performed (** $p<0.01, n=5$, unmatched two-way ANOVA, Bonferroni post hoc test). All data is displayed as mean \pm SEM with treatment concentration on the $x$ axis. in hallmark pro-inflammatory cytokines IL-1 $\beta$, IL-6 and TNF $\alpha$ and resulted in neuro-protection against soluble $A \beta$. We show that knockdown of IRF7 is sufficient to abolish the type-1 IFN response to both the selective TLR4 agonist LPS and the indiscriminate TLR ligand A $31-42$ in human neuroblastoma M17 BE(2) cells. Furthermore, IRF7 knockdown resulted in protection against A $1-42$ toxicity.

TLRs, a super-family of pattern recognition receptors, are the host's primary detectors of foreign pathogens and mediate the initial type-1 IFN response in the innate immune response [67]. A myriad of TLR subtypes are capable of detecting $A \beta$ and initiating an innate immune response against the neurotoxic peptide $[57,68,69]$. Myd88 is a critical adaptor protein for all TLR signalling except for TLR3 and Myd88-independent TLR4 activation. The involvement of Myd88 in animal models of amyloidosis remains controversial and somewhat conflicted. Mice over-expressing APP and PS1 on a Myd88 ${ }^{-/-}$background showed reduced soluble and insoluble amyloid load at 10 months correlating with reductions in reactive astrogliosis and microglial activation [22]. These same mice appeared to show no spatial learning improvement in the Morris water maze compared to $\mathrm{APP}_{\mathrm{swe}} / \mathrm{PS}_{\triangle \mathrm{E} 9}$ mice alone but interestingly, removal of Myd88 was sufficient to improve this outcome regardless of transgene expression [23]. $\mathrm{APP}_{\mathrm{swe}} / \mathrm{PS} 1_{\triangle \mathrm{E} 9}$ mice on a heterozygous Myd88 background also showed reduced plaque deposition but elevated soluble $A \beta$ levels. These mice were found to have reduced brain IL$1 \beta$ mRNA and had accelerated spatial memory deficits in the T-water maze [24]. Most recently, $\mathrm{APP}_{\text {swe }} / \mathrm{PS}_{\triangle \mathrm{E} 9}$ mice on a Myd88 deficient background showed no changes in amyloid levels or immune cell infiltration but displayed a reduced life expectancy [70]. All these reports ultimately focus on the astrocyte and microglial response to amyloid load and how Myd88 absence affects this process. Still, there remain conflicting conclusions arising from these animal models.

Neuro-inflammation is an intricate process with multiple signalling cascades and critical cellular processes driving pathogen clearance. Our study aimed to simplify 
the previously conducted in vivo studies and used a controlled in vitro approach to assess the impact of Myd88 signalling in response to soluble amyloid. In this study, we focus on the impact of Myd88 removal in neurons and how this may alter the type-1 IFN response to the amyloid peptide. Removal of Myd88 in primary neuronal cultures conferred reductions in type-1 IFNs and hallmark pro-inflammatory cytokines IL-1 $\beta$, IL- 6 and TNF $\alpha$ compared to wildtype when challenged with A $\beta 1-42$. This reduction in pro-inflammatory cytokine expression in the Myd88 ${ }^{-1-}$ cells also coincided with decreased p-STAT-3 levels, a downstream type-1IFN signalling mediator. This data supports the hypothesis that the TLR network is responsible for detecting soluble amyloid [19]. Furthermore, we hypothesise that the neuronal type-1 IFN response to amyloid occurs via a TLR-mediated mechanism. This type- 1 IFN response is biphasic in nature which remains a common characteristic of the type-1 IFN signature displayed upon pathogenic infection [71-73]. This release begins from $24 \mathrm{~h}$ post-A $\beta$ insult, returns to baseline by $48 \mathrm{~h}$ and enters a secondary ramping phase from $72 \mathrm{~h}$. The lack of significant difference between the wildtype and $\mathrm{Myd} 88^{-/-}$ neuronal type- 1 IFN expression pattern at $48 \mathrm{~h}$ post- $\mathrm{A} \beta$ treatment can be explained by the existence of this wildtype biphasic response.

It is well accepted that a neuro-inflammatory environment, if not controlled, is deleterious to neuronal viability and disease progression. IL-1 $\beta$, IL- 6 and TNF $\alpha$ remain as hallmark pro-inflammatory cytokines that can trigger necrosis, apoptosis and excitotoxicity. We have shown that $\mathrm{Myd} 88^{-/-}$neuronal cultures, with reduced pro-inflammatory cytokine load, are protected against A $11-42$ when compared to wildtype cells. These findings suggest that limiting the pro-inflammatory environment induced by amyloid, at least in a neuronal context, is beneficial in promoting neuro-protection. Neuro-inflammation is a complex but coordinated event that is tightly regulated by specific cellular processes but also the timing in which they occur. The timing of individual pro-inflammatory cytokine and chemokine release is crucial in recruitment of immune cells to the inflamed site and ensuring that this microenvironment facilitates an efficient immune response. Our data suggests that neurons, in response to amyloid, release an initial short-term interleukin pro-inflammatory component and potentiated TNF $\alpha$ component that correlates well with the time frame of $\mathrm{A} \beta 1$-42-induced neurotoxicity. Whilst IL-1 $\beta$, IL- 6 and TNF $\alpha$ pro-inflammatory cytokine secretions in neuro-inflammation share great interplay, the regulatory mechanisms governing their production differ [74-77]. Type-1 IFNs remain critical to the inflammatory response and can regulate the NALP3 inflammasome responsible for IL- $1 \beta$ production [78], previously implicated in AD pathology [10]. It remains unclear if alterations in type-1 IFN expression alone are sufficient to modulate the $A \beta$ inflammasome or if other signalling pathways are involved, providing scope for further investigation.

Type-1 IFN production involves multiple signalling cascades. Although TLR activation is a primary source of type-1 IFNs [28], other pattern recognition receptors can also be responsible. Retinoic acid-inducible gene-1 (RIG1), melanoma differentiation-associated protein-5 (MDA5) and interferon gamma-inducible protein 16 (IFI-16) are all examples of TLR-independent activators of the type-1 IFN response [29]. Furthermore, complement can stimulate plasmacytoid dendritic cells to produce IFN $\alpha$ [79] and is a major component of the innate immune response. Despite this myriad of potential type-1 IFN secretion pathways, they all converge on the phosphorylation/activation of IRFs to initiate type-1 IFN gene transcription. Specifically, IRF7 is required for type-1 IFN production [61] and is an important regulator for many of the aforementioned innate immunity signalling cascades. Upon stimulation of human neuroblastoma M17 cell cultures with the TLR4 agonist LPS we found that IRF7 knockdown was sufficient to ablate the type-1 IFN response to the bacterial endotoxin. This data supports previous dogma that stimulation of TLR4 induces a type-1 IFN response through IRF7 activation [80,81]. Initially, this response is mediated by a TRIF-dependent interaction but subsequent type-1 IFN production remains Myd88 dependent [82]. LPS induces a well-characterised TLR4-mediated response and is useful as a pharmacological tool in this respect; however, $A \beta$ as an endogenous pathogenic ligand interacts with numerous receptors associated with the innate immune system [19]. We identified that knockdown of IRF7 was sufficient to decrease type-1 IFN expression and downstream p-STAT3 signalling in response to $A \beta 1-42$. This similarity between the type-1 IFN release profile from cultures stimulated with either LPS or A $\beta$ infers that TLR4 detection of amyloid contributes to the net type-1 IFN response. Under conditions of neuronal stress [83] or innate immune system priming [82], TLR4 signalling can induce a robust IRF7-dependent type-1IFN response. Our findings suggest that a TLR4-IRF7 driven type-1 IFN response is involved in the cellular response to soluble amyloid.

Alongside IRF7, IRF3 is also critical in producing a type-1 IFN response to pathogenic material [84]. TLR4 activation leads to the formation of the TBK1/IKKi complex and can phosphorylate both IRF3 [85] and IRF7 [86] leading to DNA binding and type-1 IFN transcription. Furthermore, activation of NFkB, downstream of TLR4, has been implicated in $A \beta$ signalling and apoptotic neurons in human AD brains $[87,88]$. NFkB is capable of modulating both IRF3 and IRF7 activation via transcription and production of pro-inflammatory cytokines [89]. The precise contribution of TLR-mediated 
activation of IRF3 in the neuronal type-1 IFN response to amyloid and potential interplay with IRF7 has yet to be explored and warrants further investigation. It is likely that TLR4 binding is a significant component of A $\beta$-induced type-1 IFN production; however, the overall response is likely to be the summation of many activated sensors of the innate immune system.

Considering $\mathrm{Myd} 88^{-/-}$neurons secrete reduced type-1 IFN in response to $A \beta$ and exhibit significant neuroprotection, we assessed viability of IRF7 knockdown M17 cultures. Similar to the Myd88 ${ }^{-1-}$ cells, M17 IRF7 KD cells were protected against A $\beta 1-42$-induced cytotoxicity. We therefore hypothesise that reducing neuronal type-1 IFN levels in response to $A \beta$ will be beneficial for cellular survival. The current study uses the A $\beta 1-42$ peptide as the sole ligand to trigger an innate immune response. As amyloid is a neurotoxic peptide, the neuronal cultures are under duress and can release DAMPs which are readily recognised by PRRs. The subsequent release of neuronal IL-1 $\beta$, IL-6 and TNFa actively contributes to the neuroinflammatory environment and drives excitotoxicity [90]. Despite amyloid-induced signalling occurring prior to that of DAMPs, it remains difficult to predict what proportion of the inflammatory response is induced purely by amyloid rather than cellular stress and debris. Delineating these pathways will be important in identifying the exact initial binding partners of $A \beta$ and may reveal novel therapeutic targets.

The concept of inflammatory homeostasis controlled by neuronal reflex activity is well established with cholinergic activity being implicated in negatively regulating proinflammatory responses $[91,92]$. Indeed, genetic ablation of the $\alpha 7$ nicotinic acetylcholine (ACh) receptor (nAChR) in mice leads to loss of vagal nerve-induced suppression of TNF $\alpha$ [93] and $\alpha 7$ agonists can significantly inhibit the cytokine production induced by pathogenic TLR ligands [94]. Indeed, cholinergic neural activity activates the $\mathrm{CREB} / \mathrm{cfos}$ transcriptional pathways leading to inhibition of $\mathrm{NFKB}$ in various innate and adaptive immune cells. TLR activation via various pathogens and $A \beta$ is a major driver of NFkB activity, and thus these two signalling pathways compete against each other to govern the proinflammatory cytokine response to pathogenic insult and/ or tissue damage [95]. In the context of $\mathrm{AD}$, patients commonly display decreased cerebral and hippocampal $\alpha 7$ nAChR expression and cholinergic activity [96]. As mentioned previously, dysregulation of the cholinergic system can lead to a pro-inflammatory imbalance and this leads to declines in executive function and brain metabolism in mice [97]. MicroRNA-132 is a negative regulator of synaptic AChesterase [98] and has recently been identified as decreased in early stages of $\mathrm{AD}$ [99], suggesting that decreased cholinergic activity and hence elevated proinflammatory cytokine load is an early event contributing to disease progression. Findings from our study reveal a novel mechanism by which TLR signalling, in opposition to cholinergic activity, drives type- 1 IFN production and pro-inflammatory cytokine secretion in response to $A \beta$. This finding highlights a potential mechanism by which neuro-inflammation is exacerbated in the absence of efficient cholinergic control in AD.

Whilst our findings support developing therapeutics which can modulate type-1 IFN levels in conditions of amyloidosis, agents targeting neuro-inflammation should be treated with caution. Type-1 IFNs are pleiotropic in nature and behave remarkably different depending on cell type. Indeed, type-1 IFNs are critical in viral immunity and beneficial inflammatory processes needed for clearance of amyloid. Targeting the TLR network therapeutically may prove a viable way of limiting type-1 IFN levels, but it is critical that the degree of modulation, the timing of therapeutic intervention and cell-type specificity be taken into account. In support of this, $\mathrm{APP}_{\mathrm{swe}} / \mathrm{PS}_{\triangle \mathrm{E} 9}$ mice carrying a non-functional TLR4 mutant allele displayed decreased microglial activation and increased amyloid deposition and were more vulnerable to spatial learning memory deficits in the Morris water maze [26]. Furthermore, TLR4 is required for microglial phagocytosis of degenerating axons and efficient removal of cellular debris [83]. In addition, mice lacking TLR9 develop a spontaneous anxious phenotype due to lack of non-canonical NFkB activation, crucial in controlling anti-inflammatory cascades [100]. It is clear from these findings that complete removal of the TLR response remains deleterious due to suppression or lack of coordination in the immune response. Rather a fine balance is required where a neuro-inflammatory response is initiated, clearance of amyloid occurs and inflammation is resolved. In $\mathrm{AD}$, where neuro-inflammation remains chronically activated, therapeutic intervention is required. Our findings identify that the neuronal type-1 IFN response to amyloid is deleterious to neuronal viability and that this response is TLR-Myd88-IRF7 dependent. This highlights a novel production pathway of the type-1 IFNs, a master regulator of innate immunity, in $A \beta$-induced neuro-inflammation. The neuronal origin of this finding highlights the importance in understanding the cellspecific responses to amyloid. This knowledge will be critical in identifying and targeting novel signalling pathways to limit both the neuro-inflammatory component and subsequent neuronal cell death of $\mathrm{AD}$.

\section{Additional files}

Additional file 1: Figure S1. Evaluation of IRF7 knockdown efficiency in human BE(2) M17 human neuroblastoma cells. M17 cells stably transfected with an IRF7 shRNA or corresponding negative control shRNA plasmid were analysed by Q-PCR to evaluate knockdown efficiencies. Data for IRF7 knockdown is expressed as fold change normalised to corresponding 
negative control transfected cells (nominal value of 1). Graphical data is displayed as mean $\pm \operatorname{SEM}(n=4)$.

Additional file 2: Table S1. TLR 2/4 expression in wildtype and

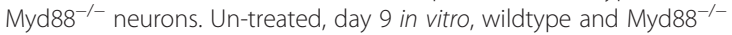
primary neuronal cultures were analysed by Q-PCR to determine TLR2 and TLR4 expression levels. Observed raw GAPDH, TLR2 and TLR4 Ct values are displayed and no reverse transcriptase (RT) and water controls remained undetermined (U.D.). Data is expressed as mean $\pm \operatorname{SEM}(n=4)$.

Additional file 3: Figure S3. Full Western blot images of $A \beta 1$-42-treated wildtype and $\mathrm{Myd} 88^{---}$neuronal cultures. Wildtype and $\mathrm{Myd} 88^{-/-}$primary cultured murine mixed cortical and hippocampal neuronal cultures were treated with $2.5 \mu \mathrm{M} \mathrm{A \beta 1-42}$ for 24 to $72 \mathrm{~h}$. Western blotting, probing for p-STAT-3, STAT-3 and $\beta$-actin, was performed as described previously within the Materials and methods section. Bands of interest were selected from the full-sized Western blot image, as indicated by the red box, and cropped. This cropped image was then subjected to uniform image enhancement of contrast and brightness to yield the publication image seen in Figure $1 C$. Molecular weights were determined using the Precision Plus Protein ${ }^{\text {TM }}$ WesternC Standard (Bio-Rad, 161-0376) that yields a colorimetric image only and has been removed from the chemiluminescent blot image.

Additional file 4: Figure S2. Aß42-1-treated neurons do not initiate a type-1 interferon response. Wildtype primary cultured murine mixed cortical and hippocampal neuronal cultures were treated with $2.5 \mu \mathrm{M}$ A $342-1$ (reverse sequence peptide) for 24 to $72 \mathrm{~h}$. (A) IFNa and (B) IFN $\beta$ mRNA levels were then analysed by Q-PCR $(n=4)$. (B) Tyrosine 705 phosphorylation of STAT-3 was detected by Western blot in these same cultures. All graphical data is displayed as mean \pm SEM with treatment time on the $x$ axis.

Additional file 5: Figure S4. The type- 1 IFN response to $A \beta 1-42$ is attenuated in an alternate clonal M17 IRF7 shRNA knockdown cell line. Human BE(2) M17 neuroblastoma cells, transfected with an IRF7 knockdown (KD) construct or negative control (NC) plasmid, were treated with $7.5 \mu \mathrm{M}$ A 1 1-42 for 24 to $96 \mathrm{~h}$. Q-PCR was performed to analyse (A) IFNa and (B) IFN $\beta$ mRNA levels post-treatment $\left({ }^{*} p<0.05,{ }^{* *} p<0.01, n=3\right.$ to 4 , unmatched two-way ANOVA, Bonferroni post hoc test). Data shown is from an alternative clonal cell line to that used in Figures 4 and 5. (C) Levels of IRF7 knockdown in these cells were also determined by Q-PCR where data is expressed as fold change normalised to corresponding negative control transfected cells (nominal value of $1, n=3$ ). Graphical data is displayed as mean \pm SEM.

Additional file 6: Figure S5. Full Western blot images of Aß1-42-treated M17 NC and IRF7 KD cell cultures. Human BE(2) M17 neuroblastoma cells, transfected with an IRF7 knockdown (KD) construct or negative control (NC) plasmid, were treated with $7.5 \mu \mathrm{M}$ A $31-42$ for 24 to $96 \mathrm{~h}$. Western blotting, probing for p-STAT-3, STAT-3 and $\beta$-actin, was performed as described previously within the Materials and methods section. Bands of interest were selected from the full-sized western blot image, as indicated by the red box, and cropped. This cropped image was then subjected to uniform image enhancement of contrast and brightness to yield the publication image seen in Figure 4E. Molecular weights were determined using the Precision Plus Protein $^{\text {TM }}$ WesternC Standard (Bio-Rad, 161-0376) that yields a colorimetric image only and has been removed from the chemiluminescent blot image.

Additional file 7: Figure S6. Full Western blot images of LPS-treated M17 NC and IRF7 KD cell cultures. Human BE(2) M17 neuroblastoma cells, transfected with an IRF7 knockdown (KD) construct or negative control (NC) plasmid, were treated with $100 \mathrm{ng} / \mathrm{ml}$ LPS for 0.5 to $24 \mathrm{~h}$. Western blotting, probing for p-STAT-3, STAT-3 and $\beta$-actin, was performed as described previously within the Materials and methods section. Bands of interest were selected from the full-sized Western blot image, as indicated by the red box, and cropped. This cropped image was then subjected to uniform image enhancement of contrast and brightness to yield the publication image seen in Figure $4 \mathrm{H}$. Molecular weights were determined using the Precision Plus Protein ${ }^{T M}$ WesternC Standard (Bio-Rad, 161-0376) that yields a colorimetric image only and has been removed from the chemiluminescent blot image.

\section{Abbreviations}

AB: amyloid-beta; ACh: acetylcholine; AD: Alzheimer's disease;

ANOVA: analysis of variance; APP: amyloid precursor protein; BACE: beta-site amyloid precursor protein cleavage enzyme; BDNF: brain-derived neurotrophic factor; CNS: central nervous system; CREB: CAMP response element-binding protein; DAMP: damage-associated molecular pattern; DAPI: 4',6-diamidino-2-phenylindole; DEPC: diethylpyrocarbonate; DNA: deoxyribonucleic acid; FBS: Foetal bovine serum; GFAP: glial fibrillary protein; IFI-16: interferon gamma-inducible protein-16; IFN: interferon; IKKi: inhibitor of NFKB kinase; IL: interleukin; IRF: interferon regulatory factor; JAK: Janus-associated kinase; KD: knockdown; LPS: lipopolysaccharide; MDA-5: melanoma differentiation-associated protein-5; Myd88: myeloid differentiation factor-88; MTS: 3-(4,5-dimethylthiazol-2-yl)-5-

(3-carboxymethoxyphenyl)-2-(4-sulfophenyl)-2H-tetrazolium; nAChR: nicotinic acetylcholine receptor; NALP: nucleotide-binding oligomerisation receptor; NC: negative control; NeuN: hexaribonucleotide binding protein-3;

NFkB: nuclear factor kappa-B; p-: phosphorylated; PBS: phosphate-buffered saline; PCR: polymerase chain reaction; PRR: pattern recognition receptor; PS: presenilin; PVDF: polyvinylidene fluoride; RIG-1: retinoic acid inducible gene-1; RNA: ribonucleic acid; SEM: standard error of the mean; STAT: signal transducer and activator of transcription; TBK-1: TANK-binding kinase-1; TBS-T: tris-buffered saline-Tween 20; TLR: toll-like receptor; TNF: tumour necrosis factor; TRIF: toll/interleukin-1-domain-containing adapter-inducing interferon- $\beta$; Tyk: tyrosine kinase.

\section{Competing interests}

The authors declare that they have no competing interests.

\section{Authors' contributions}

MRM, BSM, KMB and MZ conducted all experiments and analysed the data. MRM, PJC and JMT designed the study and wrote the manuscript. PJC and JMT contributed to all data analysis. All authors discussed the results and commented on the manuscript. All authors read and approved the final manuscript.

\section{Acknowledgements}

This study was supported by grants from the National Health and Medical Research Council (NHMRC) of Australia to PJC and JMT. PJC is an Australian Research Council (ARC) Future Fellow. MRM holds an Alzheimer's Australia Dementia Research Fund (AADRF) postgraduate scholarship.

\section{Received: 3 December 2014 Accepted: 9 February 2015}

\section{Published online: 12 April 2015}

\section{References}

1. Grundke-labal I, labal K, Tung YC, Quinlan M, Wisniewski HM, Binder LI. Abnormal phosphorylation of the microtubule-associated protein tau (tau) in Alzheimer cytoskeletal pathology. Proc Natl Acad Sci U S A. 1986:83:4913-7.

2. Selkoe DJ. Alzheimer's disease results from the cerebral accumulation and cytotoxicity of amyloid beta-protein. J Alzheimers Dis. 2001;3:75-80.

3. Tahara K, Kim HD, Jin JJ, Maxwell JA, Li L, Fukuchi K. Role of toll-like receptor signalling in Abeta uptake and clearance. Brain. 2006;129:3006-19.

4. Apelt J, Schliebs R. Beta-amyloid-induced glial expression of both pro- and anti-inflammatory cytokines in cerebral cortex of aged transgenic Tg2576 mice with Alzheimer plaque pathology. Brain Res. 2001;894:21-30.

5. Salminen A, Ojala J, Suuronen T, Kaarniranta K, Kauppinen A. Amyloid-beta oligomers set fire to inflammasomes and induce Alzheimer's pathology. J Cell Mol Med. 2008;12:2255-62.

6. Blasko I, Marx F, Steiner E, Hartmann T, Grubeck-Loebenstein B. TNFalpha plus IFNgamma induce the production of Alzheimer beta-amyloid peptides and decrease the secretion of APPS. FASEB J. 1999;13:63-8.

7. Hanisch UK. Microglia as a source and target of cytokines. Glia. 2002;40:140-55.

8. Ye L, Huang $Y$, Zhao L, Li Y, Sun L, Zhou Y, et al. IL-1 beta and TNF-alpha induce neurotoxicity through glutamate production: a potential role for neuronal glutaminase. J Neurochem. 2013;125:897-908.

9. Floden AM, Combs CK. Beta-amyloid stimulates murine postnatal and adult microglia cultures in a unique manner. J Neurosci. 2006;26:4644-8.

10. Heneka MT, Kummer MP, Stutz A, Delekate A, Schwartz S, Vieira-Saecker A, et al. NLRP3 is activated in Alzheimer's disease and contributes to pathology in APP/PS1 mice. Nature. 2013:493:674-8.

11. Taylor JM, Minter MR, Newman AG, Zhang M, Adlard PA, Crack PJ. Type-1 interferon signaling mediates neuro-inflammatory events in models of Alzheimer's disease. Neurobiol Aging. 2014;35:1012-23. 
12. Novikov A, Cardone M, Thompson R, Shenderov K, Kirschman KD, Mayer-Barber $\mathrm{KD}$, et al. Mycobacterium tuberculosis triggers host type I IFN signaling to regulate IL-1beta production in human macrophages. J Immunol. 2011;187:2540-7.

13. Hornung V, Ablasser A, Charrel-Dennis M, Bauernfeind F, Horvath G, Caffrey DR, et al. AIM2 recognizes cytosolic dsDNA and forms a caspase-1-activating inflammasome with ASC. Nature. 2009;458:514-8.

14. Downes CE, Crack PJ. Neural injury following stroke: are toll-like receptors the link between the immune system and the CNS? Br J Pharmacol. 2010;160:1872-88.

15. Kawai T, Akira S. Toll-like receptor and RIG-l-like receptor signaling. Ann N Y Acad Sci. 2008;1143:1-20

16. Kawai T, Akira S. Signaling to NF-kappaB by toll-like receptors. Trends Mol Med. 2007;13:460-9.

17. Nishimura M, Naito S. Tissue-specific mRNA expression profiles of human toll-like receptors and related genes. Biol Pharm Bull. 2005;28:886-92.

18. Mishra BB, Mishra PK, Teale JM. Expression and distribution of toll-like receptors in the brain during murine neurocysticercosis. J Neuroimmunol. 2006;181:46-56.

19. Salminen A, Ojala J, Kauppinen A, Kaarniranta K, Suuronen T. Inflammation in Alzheimer's disease: amyloid-beta oligomers trigger innate immunity defence via pattern recognition receptors. Prog Neurobiol. 2009;87:181-94.

20. Liu Y, Walter S, Stagi M, Cherny D, Letiembre M, Schulz-Schaeffer W, et al. LPS receptor (CD14): a receptor for phagocytosis of Alzheimer's amyloid peptide. Brain. 2005;128:1778-89.

21. Reed-Geaghan EG, Savage JC, Hise AG, Landreth GE. CD14 and toll-like receptors 2 and 4 are required for fibrillar A\{beta\}-stimulated microglial activation. J Neurosci. 2009;29:11982-92.

22. Lim JE, Kou J, Song M, Pattanayak A, Jin J, Lalonde R, et al. MyD88 deficiency ameliorates beta-amyloidosis in an animal model of Alzheimer's disease. Am J Pathol. 2011;179:1095-103.

23. Lim JE, Song M, Jin J, Kou J, Pattanayak A, Lalonde R, et al. The effects of MyD88 deficiency on exploratory activity, anxiety, motor coordination, and spatial learning in C57BL/6 and APPswe/PS1dE9 mice. Behav Brain Res. 2012;227:36-42.

24. Michaud JP, Richard KL, Rivest S. MyD88-adaptor protein acts as a preventive mechanism for memory deficits in a mouse model of Alzheimer's disease. Mol Neurodegener. 2011;6:5

25. Jin JJ, Kim HD, Maxwell JA, Li L, Fukuchi K. Toll-like receptor 4-dependent upregulation of cytokines in a transgenic mouse model of Alzheimer's disease. J Neuroinflammation. 2008;5:23.

26. Song M, Jin J, Lim JE, Kou J, Pattanayak A, Rehman JA, et al. TLR4 mutation reduces microglial activation, increases Abeta deposits and exacerbates cognitive deficits in a mouse model of Alzheimer's disease. J Neuroinflammation. 2011:8:92.

27. de Weerd NA, Nguyen T. The interferons and their receptors - distribution and regulation. Immunol Cell Biol. 2012;90:483-91.

28. Medzhitov R. Toll-like receptors and innate immunity. Nat Rev Immunol. 2001;1:135-45

29. Barbalat R, Ewald SE, Mouchess ML, Barton GM. Nucleic acid recognition by the innate immune system. Annu Rev Immunol. 2011;29:185-214.

30. Kawai T, Akira S. Innate immune recognition of viral infection. Nat Immunol. 2006;7:131-7.

31. de Weerd NA, Samarajiwa SA, Hertzog PJ. Type I interferon receptors: biochemistry and biological functions. J Biol Chem. 2007;282:20053-7.

32. Wan J, Fu AK, Ip FC, Ng HK, Hugon J, Page G, et al. Tyk2/STAT3 signaling mediates beta-amyloid-induced neuronal cell death: implications in Alzheimer's disease. J Neurosci. 2010;30:6873-81.

33. Honda K, Taniguchi T. IRFs: master regulators of signalling by toll-like receptors and cytosolic pattern-recognition receptors. Nat Rev Immunol. 2006;6:644-58.

34. Yang $H$, Lin $\mathrm{CH}, \mathrm{Ma} G$, Baffi MO, Wathelet MG. Interferon regulatory factor-7 synergizes with other transcription factors through multiple interactions with p300/CBP coactivators. J Biol Chem. 2003;278:15495-504.

35. Lee MN, Ye C, Villani AC, Raj T, Li W, Eisenhaure TM, et al. Common genetic variants modulate pathogen-sensing responses in human dendritic cells. Science. 2014:343:1246980.

36. Baruch K, Deczkowska A, David E, Castellano JM, Miller O, Kertser A, et al. Aging. Aging-induced type I interferon response at the choroid plexus negatively affects brain function. Science. 2014;346:89-93.

37. Ning S, Pagano JS, Barber GN. IRF7: activation, regulation, modification and function. Genes Immun. 2011;12:399-414.
38. Kim TW, Staschke K, Bulek K, Yao J, Peters K, Oh KH, et al. A critical role for IRAK4 kinase activity in toll-like receptor-mediated innate immunity. J Exp Med. 2007;204:1025-36.

39. Koziczak-Holbro M, Joyce C, Gluck A, Kinzel B, Muller M, Tschopp C, et al. IRAK-4 kinase activity is required for interleukin-1 (IL-1) receptor- and toll-like receptor 7-mediated signaling and gene expression. J Biol Chem. 2007;282:13552-60.

40. Konno H, Yamamoto T, Yamazaki K, Gohda J, Akiyama T, Semba K, et al. TRAF6 establishes innate immune responses by activating NF-kappaB and IRF7 upon sensing cytosolic viral RNA and DNA. PLoS One. 2009;4, e5674.

41. Kawai T, Sato S, Ishii KJ, Coban C, Hemmi H, Yamamoto M, et al. Interferon-alpha induction through Toll-like receptors involves a direct interaction of IRF7 with MyD88 and TRAF6. Nat Immunol. 2004;5:1061-8.

42. Marie I, Durbin JE, Levy DE. Differential viral induction of distinct interferonalpha genes by positive feedback through interferon regulatory factor-7. EMBO J. 1998;17:6660-9.

43. Sato M, Hata N, Asagiri M, Nakaya T, Taniguchi T, Tanaka N. Positive feedback regulation of type I IFN genes by the IFN-inducible transcription factor IRF-7. FEBS Lett. 1998;441:106-10.

44. Adachi O, Kawai T, Takeda K, Matsumoto M, Tsutsui H, Sakagami M, et al. Targeted disruption of the MyD88 gene results in loss of IL-1- and IL-18mediated function. Immunity. 1998;9:143-50.

45. Downes CE, Wong CH, Henley KJ, Guio-Aguilar PL, Zhang M, Ates R, et al. MyD88 is a critical regulator of hematopoietic cell-mediated neuroprotection seen after stroke. PLoS One. 2013;8, e57948.

46. Barnham KJ, Ciccotosto GD, Tickler AK, Ali FE, Smith DG, Williamson NA, et al. Neurotoxic, redox-competent Alzheimer's beta-amyloid is released from lipid membrane by methionine oxidation. J Biol Chem. 2003;278:42959-65.

47. Huang X, Cuajungco MP, Atwood CS, Hartshorn MA, Tyndall JD, Hanson GR, et al. $\mathrm{Cu}(\mathrm{II})$ potentiation of Alzheimer Abeta neurotoxicity. Correlation with cell-free hydrogen peroxide production and metal reduction. J Biol Chem. 1999;274:37111-6.

48. Adlard PA, Cherny RA, Finkelstein DI, Gautier E, Robb E, Cortes M, et al. Rapid restoration of cognition in Alzheimer's transgenic mice with 8hydroxy quinoline analogs is associated with decreased interstitial Abeta. Neuron. 2008:59:43-55.

49. Varadarajan S, Kanski J, Aksenova M, Lauderback C, Butterfield DA. Different mechanisms of oxidative stress and neurotoxicity for Alzheimer's A beta (1-42) and A beta(25-35). J Am Chem Soc. 2001;123:5625-31.

50. Hung LW, Ciccotosto GD, Giannakis E, Tew DJ, Perez K, Masters CL, et al. Amyloid-beta peptide (Abeta) neurotoxicity is modulated by the rate of peptide aggregation: Abeta dimers and trimers correlate with neurotoxicity. J Neurosci. 2008;28:11950-8.

51. Smith JP, Lal V, Bowser D, Cappai R, Masters CL, Ciccotosto GD. Stimulus pattern dependence of the Alzheimer's disease amyloid-beta 42 peptide's inhibition of long term potentiation in mouse hippocampal slices. Brain Res. 2009;1269:176-84

52. Ciccotosto GD, Tew D, Curtain CC, Smith D, Carrington D, Masters CL, et al, Enhanced toxicity and cellular binding of a modified amyloid beta peptide with a methionine to valine substitution. J Biol Chem. 2004;279:42528-34.

53. Schmid AW, Freir DB, Herron CE. Inhibition of LTP in vivo by beta-amyloid peptide in different conformational states. Brain Res. 2008;1197:135-42.

54. Smith DP, Ciccotosto GD, Tew DJ, Fodero-Tavoletti MT, Johanssen T, Masters $\mathrm{CL}$, et al. Concentration dependent $\mathrm{Cu} 2+$ induced aggregation and dityrosine formation of the Alzheimer's disease amyloid-beta peptide. Biochemistry. 2007:46:2881-91.

55. Livak KJ, Schmittgen TD. Analysis of relative gene expression data using real-time quantitative PCR and the 2(-Delta Delta C(T)) Method. Methods. 2001;25:402-8

56. Buttke TM, McCubrey JA, Owen TC. Use of an aqueous soluble tetrazolium/ formazan assay to measure viability and proliferation of lymphokinedependent cell lines. J Immunol Methods. 1993;157:233-40.

57. Liu S, Liu Y, Hao W, Wolf L, Kiliaan AJ, Penke B, et al. TLR2 is a primary receptor for Alzheimer's amyloid beta peptide to trigger neuroinflammatory activation. J Immunol. 2012;188:1098-107.

58. Gao M, London N, Cheng K, Tamura R, Jin J, Schueler-Furman O, et al. Rationally designed macrocyclic peptides as synergistic agonists of LPS-induced inflammatory response. Tetrahedron. 2014;70:7664-8.

59. Oda M, Yamamoto H, Shibutani M, Nakano M, Yabiku K, Tarui T, et al. Vizantin inhibits endotoxin-mediated immune responses via the TLR 4/MD-2 complex. J Immunol. 2014;193:4507-14. 
60. Zhang YY, Fan YC, Wang M, Wang D, Li XH. Atorvastatin attenuates the production of IL-1beta, IL-6, and TNF-alpha in the hippocampus of an amyloid beta1-42-induced rat model of Alzheimer's disease. Clin Interv Aging. 2013;8:103-10.

61. Honda K, Yanai H, Negishi H, Asagiri M, Sato M, Mizutani T, et al. IRF-7 is the master regulator of type-I interferon-dependent immune responses. Nature. 2005;434:772-7.

62. Terry RD. The pathogenesis of Alzheimer disease: an alternative to the amyloid hypothesis. J Neuropathol Exp Neurol. 1996;55:1023-5.

63. McLean CA, Cherny RA, Fraser FW, Fuller SJ, Smith MJ, Beyreuther K, et al. Soluble pool of Abeta amyloid as a determinant of severity of neurodegeneration in Alzheimer's disease. Ann Neurol. 1999;46:860-6.

64. Lue LF, Kuo YM, Roher AE, Brachova L, Shen $Y$, Sue L, et al. Soluble amyloid beta peptide concentration as a predictor of synaptic change in Alzheimer's disease. Am J Pathol. 1999;155:853-62

65. Brun A, Englund E. Regional pattern of degeneration in Alzheimer's disease: neuronal loss and histopathological grading. Histopathology. 1981;5:549-64.

66. Whitehouse PJ, Price DL, Struble RG, Clark AW, Coyle JT, Delon MR. Alzheimer's disease and senile dementia: loss of neurons in the basal forebrain. Science. 1982;215:1237-9.

67. Owens T, Khorooshi R, Wlodarczyk A, Asgari N. Interferons in the central nervous system: a few instruments play many tunes. Glia. 2014;62:339-55.

68. Tang SC, Lathia JD, Selvaraj PK, Jo DG, Mughal MR, Cheng A, et al. Toll-like receptor-4 mediates neuronal apoptosis induced by amyloid beta-peptide and the membrane lipid peroxidation product 4-hydroxynonenal. Exp Neurol. 2008;213:114-21.

69. Stewart CR, Stuart LM, Wilkinson K, van Gils JM, Deng J, Halle A, et al. CD36 ligands promote sterile inflammation through assembly of a toll-like receptor 4 and 6 heterodimer. Nat Immunol. 2010;11:155-61.

70. Goll Y, Bekenstein U, Barbash S, Greenberg DS, Zangen R, Shoham S, et al. Sustained Alzheimer's amyloid pathology in myeloid differentiation protein88-deficient APPswe/PS1 mice. Neuro-degenerative Diseases. 2014;13:58-60.

71. Hwang SY, Hur KY, Kim JR, Cho KH, Kim SH, Yoo JY. Biphasic RLR-IFN-beta response controls the balance between antiviral immunity and cell damage. J Immunol. 2013;190:1192-200.

72. Meylan E, Tschopp J. Toll-like receptors and RNA helicases: two parallel ways to trigger antiviral responses. Mol Cell. 2006;22:561-9.

73. Schneider K, Loewendorf A, De Trez C, Fulton J, Rhode A, Shumway H, et al. Lymphotoxin-mediated crosstalk between $B$ cells and splenic stroma promotes the initial type I interferon response to cytomegalovirus. Cell Host Microbe. 2008;3:67-76.

74. Erta M, Quintana A, Hidalgo J. Interleukin-6, a major cytokine in the central nervous system. Int J Biol Sci. 2012;8:1254-66.

75. Frankola KA, Greig NH, Luo W, Tweedie D. Targeting TNF-alpha to elucidate and ameliorate neuroinflammation in neurodegenerative diseases. CNS \& Neurol Disord Drug Targets. 2011;10:391-403.

76. Shaftel SS, Griffin WS, O'Banion MK. The role of interleukin-1 in neuroinflammation and Alzheimer disease: an evolving perspective. J Neuroinflammation. 2008;5:7.

77. Singhal G, Jaehne EJ, Corrigan F, Toben C, Baune BT. Inflammasomes in neuroinflammation and changes in brain function: a focused review. Front Neurosci. 2014;8:315

78. Rathinam VA, Vanaja SK, Waggoner L, Sokolovska A, Becker C, Stuart LM, et al. TRIF licenses caspase-11-dependent NLRP3 inflammasome activation by gram-negative bacteria. Cell. 2012;150:606-19.

79. Lood C, Gullstrand B, Truedsson L, Olin Al, Alm GV, Ronnblom L, et al. C1q inhibits immune complex-induced interferon-alpha production in plasmacytoid dendritic cells: a novel link between C1q deficiency and systemic lupus erythematosus pathogenesis. Arthritis Rheum. 2009;60:3081-90.

80. Fitzgerald KA, Rowe DC, Barnes BJ, Caffrey DR, Visintin A, Latz E, et al. LPS-TLR4 signaling to IRF-3/7 and NF-kappaB involves the toll adapters TRAM and TRIF. J Exp Med. 2003:198:1043-55.

81. Ogasawara N, Sasaki M, Itoh Y, Tokudome K, Kondo Y, Ito Y, et al. Rebamipide suppresses TLR-TBK1 signaling pathway resulting in regulating IRF3/7 and IFN-alpha/beta reduction. J Clin Biochem Nutr. 2011;48:154-60.

82. Richez C, Yasuda K, Watkins AA, Akira S, Lafyatis R, van Seventer JM, et al. TLR4 ligands induce IFN-alpha production by mouse conventional dendritic cells and human monocytes after IFN-beta priming. J Immunol. 2009;182:820-8.
83. Rajbhandari L, Tegenge MA, Shrestha S, Ganesh Kumar N, Malik A, Mithal A, et al. Toll-like receptor 4 deficiency impairs microglial phagocytosis of degenerating axons. Glia. 2014;62:1982-91.

84. Sakaguchi S, Negishi H, Asagiri M, Nakajima C, Mizutani T, Takaoka A, et al. Essential role of IRF-3 in lipopolysaccharide-induced interferon-beta gene expression and endotoxin shock. Biochem Biophys Res Commun. 2003;306:860-6.

85. Fitzgerald KA, McWhirter SM, Faia KL, Rowe DC, Latz E, Golenbock DT, et al. IKKepsilon and TBK1 are essential components of the IRF3 signaling pathway. Nat Immunol. 2003:4:491-6.

86. Sharma S. tenOever BR, Grandvaux N, Zhou GP, Lin R, Hiscott J. Triggering the interferon antiviral response through an IKK-related pathway. Science. 2003:300:1148-51.

87. Kaltschmidt B, Uherek M, Wellmann H, Volk B, Kaltschmidt C. Inhibition of NF-kappaB potentiates amyloid beta-mediated neuronal apoptosis. Proc Natl Acad Sci U S A. 1999;96:9409-14.

88. Terai K, Matsuo A, McGeer PL. Enhancement of immunoreactivity for NF-kappa B in the hippocampal formation and cerebral cortex of Alzheimer's disease. Brain Res. 1996;735:159-68.

89. Moynagh PN. TLR signalling and activation of IRFs: revisiting old friends from the NF-kappaB pathway. Trends Immunol. 2005;26:469-76.

90. Acarin L, Gonzalez B, Castellano B. Neuronal, astroglial and microglial cytokine expression after an excitotoxic lesion in the immature rat brain. Eur J Neurosci. 2000;12:3505-20.

91. Borovikova LV, Ivanova S, Zhang M, Yang H, Botchkina Gl, Watkins LR, et al. Vagus nerve stimulation attenuates the systemic inflammatory response to endotoxin. Nature. 2000;405:458-62.

92. Tracey KJ. The inflammatory reflex. Nature. 2002;420:853-9.

93. Wang H, Yu M, Ochani M, Amella CA, Tanovic M, Susarla S, et al. Nicotinic acetylcholine receptor alpha7 subunit is an essential regulator of inflammation. Nature. 2003;421:384-8.

94. Rosas-Ballina M, Goldstein RS, Gallowitsch-Puerta M, Yang L, Valdes-Ferrer SI, Patel NB, et al. The selective alpha7 agonist GTS-21 attenuates cytokine production in human whole blood and human monocytes activated by ligands for TLR2, TLR3, TLR4, TLR9, and RAGE. Mol Med. 2009;15:195-202.

95. Andersson U, Tracey KJ. Reflex principles of immunological homeostasis. Annu Rev Immunol. 2012;30:313-35.

96. Lombardo S, Maskos U. Role of the nicotinic acetylcholine receptor in Alzheimer's disease pathology and treatment. Neuropharmacology. 2014;doi:10.1016/j.neuropharm.2014.11.018 [Epub].

97. Kolisnyk B, Al-Onaizi MA, Hirata PH, Guzman MS, Nikolova S, Barbash S, et al. Forebrain deletion of the vesicular acetylcholine transporter results in deficits in executive function, metabolic, and RNA splicing abnormalities in the prefrontal cortex. J Neurosci Off J Soc Neurosci. 2013;33:14908-20.

98. Shaltiel G, Hanan M, Wolf Y, Barbash S, Kovalev E, Shoham S, et al. Hippocampal microRNA-132 mediates stress-inducible cognitive deficits through its acetylcholinesterase target. Brain Struct Funct. 2013;218:59-72.

99. Lau P, Bossers K, Janky R, Salta E, Frigerio CS, Barbash S, et al. Alteration of the microRNA network during the progression of Alzheimer's disease. EMBO Mol Med. 2013;5:1613-34.

100. Zimmerman G, Shaltiel G, Barbash S, Cohen J, Gasho CJ, Shenhar-Tsarfaty S, et al. Post-traumatic anxiety associates with failure of the innate immune receptor TLR9 to evade the pro-inflammatory NFkappaB pathway. Transl Psychiatry. 2012;2, e78.

\section{Submit your next manuscript to BioMed Central and take full advantage of:}

- Convenient online submission

- Thorough peer review

- No space constraints or color figure charges

- Immediate publication on acceptance

- Inclusion in PubMed, CAS, Scopus and Google Scholar

- Research which is freely available for redistribution 